\title{
A meta-analysis of the efficacy of postoperative adjuvant radiotherapy versus no radiotherapy for extrahepatic cholangiocarcinoma and gallbladder carcinoma
}

Bixin Ren ${ }^{1,2,3+}$, Qi Guo ${ }^{1,2,3+}$, Yongqiang Yang ${ }^{1,2,3+}$, Lei Liu ${ }^{1,2,3}$, Shaohua Wei ${ }^{4}$, Wei Chen ${ }^{4}$ and Ye Tian ${ }^{1,2,3^{*}}$

\begin{abstract}
Objective: The benefit of adjuvant radiotherapy (ART) for extrahepatic cholangiocarcinoma (EHCC) and gallbladder carcinoma $(\mathrm{GBC})$ is unclear, with conflicting results from nonrandomized studies. We reported a meta-analysis to determine the impact of adjuvant radiotherapy on survival.

Methods: PubMed, EMBASE, Cochrane Library and CNKI databases were searched to identify clinical trials of postoperative ART versus no radiotherapy for EHCC and GBC. The obtained data were analyzed using RevMan 5.3 and Stata 14.0 statistical software. Differences between two groups were estimated by calculating the odds ratio $(\mathrm{OR})$ and $95 \%$ confidence interval $(\mathrm{Cl})$.

Results: A total of 21 clinical trials involving 1465 EHCC and GBC patients were selected according to the inclusion and exclusion criteria and included in this meta-analysis. The meta-analysis showed the following: The 5 -year overall survival (OS) rate was higher in the ART group than in the no radiotherapy group (OR $=0.63 ; 95 \%$ $\mathrm{Cl}=0.50-0.81, p=0.0002)$. The 5 -year OS rate was significantly higher for those with lymph node-positive disease $(\mathrm{OR}=0.15 ; 95 \% \mathrm{Cl} 0.07-0.35 ; p<0.00001)$ and margin-positive disease $(\mathrm{OR}=0.40 ; 95 \% \mathrm{Cl} 0.19-0.85 ; p=0.02)$ in the ART group than in the no radiotherapy group. ART had a tendency to bring benefit to the 5 -year OS of patients with margin-negative disease but the difference was not statistically significant $(\mathrm{OR}=0.57,95 \% \mathrm{Cl} 0.30-1$, $07, p=0.08$ ). The local recurrence rate was significantly lower in the ART group than in the no radiotherapy group $(\mathrm{OR}=0.54 ; 95 \% \mathrm{Cl}=0.38-0.76, p=0.0004)$, and there was no significant difference in the distant metastasis rate between the two groups $(\mathrm{OR}=1.33 ; 95 \% \mathrm{Cl}=0.95-1.87, p=0.10)$.
\end{abstract}

Conclusions: A meta-analysis of the existing study results showed that compared with no radiotherapy, ART is an effective postoperative treatment for EHCC and GBC.

Keywords: Extrahepatic cholangiocarcinoma, Gallbladder carcinoma, Adjuvant therapy, Radiotherapy, Meta-analysis

\footnotetext{
*Correspondence: dryetian@126.com

${ }^{\dagger}$ Bixin Ren, Qi Guo and Yongqiang Yang contributed equally to this work.

'Department of Radiotherapy \& Oncology, The Second Affiliated Hospital of Soochow University, Suzhou, China

${ }^{2}$ Institute of Radiotherapy \& Oncology, Soochow University, Suzhou, China

Full list of author information is available at the end of the article
}

(c) The Author(s). 2020 Open Access This article is distributed under the terms of the Creative Commons Attribution 4.0 International License (http://creativecommons.org/licenses/by/4.0/), which permits unrestricted use, distribution, and reproduction in any medium, provided you give appropriate credit to the original author(s) and the source, provide a link to the Creative Commons license, and indicate if changes were made. The Creative Commons Public Domain Dedication waiver (http://creativecommons.org/publicdomain/zero/1.0/) applies to the data made available in this article, unless otherwise stated. 


\section{Introduction}

Extrahepatic cholangiocarcinoma (EHCC) and gallbladder carcinoma $(\mathrm{GBC})$ are rare, with approximately 12 , 360 new cases projected to occur in the United States in 2019 [1]. The prognosis of these cancers is typically poor, with a 5-year overall survival (OS) rate ranging from 5 to 19\% [2]. The 5 -year OS rate of patients who underwent surgery was reported to be 27 to $37 \%$ [3]. Obviously, surgical treatment can improve the 5-year OS. However, the risks of local invasion, lymph node metastasis and distant metastasis of EHCC and GBC are high, and these tumors are close to the complex anatomy of the porta hepatis, which limits surgery to some extent $[2,4-6]$. Even after surgical treatment, the recurrence rate is very high; more than half of these patients experience recurrence after radical surgery, with local recurrence after resection being typically observed [7-10]. Although radiotherapy is an effective local treatment for eradicating potentially microscopic disease, the efficiency of adjuvant radiotherapy in EHCC and GBC patients is not clear.

Data supporting ART are sparse, and no consensus has been reached. Some studies have reported that patients can benefit from ART only early in the disease course but cannot benefit in the long-term [11-13]. At present, most published studies on ART for EHCC and GBC have been retrospective studies. Unfortunately, large randomized adjuvant trial evidence is difficult to obtain due to the relative rarity of EHCC and GBC. Therefore, we performed a systematic review and metaanalysis to investigate on the use of ART in EHCC and GBC patients and to clarify its effect on the 5-year OS and relapse of these patients, including the incidence of local recurrence and distant metastasis. To the best of our knowledge, no meta-analysis has yet evaluated the impact of ART on these outcomes in this patient population. Our study highlighted the benefit of long-term survival (5-year OS) and the effect of ART on local recurrence and distant metastasis. Confirmation of the effects of ART on this population and the identification of disease subgroups that would benefit from such a strategy will help guide the design of a prospective, randomized study for this rare disease. In addition, the results of this study can serve as a reference for clinicians.

\section{Methods}

\section{Literature search strategy}

Literature searches of PubMed, EMBASE, and Cochrane Library and CNKI (China National Knowledge Infrastructure) databases were performed from the date of inception to March 2019. Searches were limited to human studies. The main keywords used for the search were 'extrahepatic cholangiocarcinoma', 'gallbladder cancer' (or neoplasms), 'bile duct cancer' (or neoplasms), 'radi.' (radiotherapy, radiation), 'chemoradi.' (chemoradiotherapy, chemoradiation, radiochemotherapy), 'adjuvant' and 'postoperative'.

\section{Selection criteria}

Trials included tumors of the gallbladder and extrahepatic, perihilar, and distal bile ducts. In the experimental group, patients underwent surgery followed by ART, irrespective of concurrent chemotherapy. In the control group, patients underwent resection alone without ART. To avoid overlapping patient data in duplicate publications, registry analyses were excluded from this analysis.

\section{Statistical methods}

Two authors extracted data independently to rule out subjective effects. The following details were extracted: study period, patient number and disease site (EHCC or $\mathrm{GBC}$ ), nodal and resection margin status, chemotherapy use, radiation type and dosage, and ART toxicity. When reported, $\mathrm{T}$ stage and overall stage were collected. The use of concurrent chemotherapy (CT) was extracted when mentioned in the text. However, due to a lack of individual data and the fact that only a percentage of patients were treated with $\mathrm{CT}$ in some cohorts, it was not possible to statistically assess the impact of concurrent systemic treatments. The outcomes were 5-year OS, local recurrence rate and distant metastasis rate. When 5 -year survival was not reported in the text, it was independently calculated from survival curves.

The relative frequency of OS at 5 years between the ART and no ART groups was expressed as the odds ratio (OR) and $95 \%$ CI. Data were extracted from the primary publications and entered into the meta-analysis using RevMan 5.3 and Stata 14.0 software. The level of heterogeneity between studies was evaluated with the Cochrane Q test and the $\mathrm{I}^{2}$ statistic. Egger's regression test was used to assess publication bias.

\section{Results \\ Studies}

After screening for the inclusion criteria and reviewing the full texts of potentially eligible studies, 21 retrospective studies were identified. Figure 1 shows the flowchart of the literature search and selection process. These studies involved 1465 patients: 753 were treated with surgery alone, and 712 received ART. The detailed characteristics of the included studies are summarized in Tables 1 and 2. Some patients in the ART group also received concurrent chemotherapy, which was variable among the studies. The median external beam radiation therapy (EBRT) dose ranged from 37.5 to $52 \mathrm{~Gy}$. 


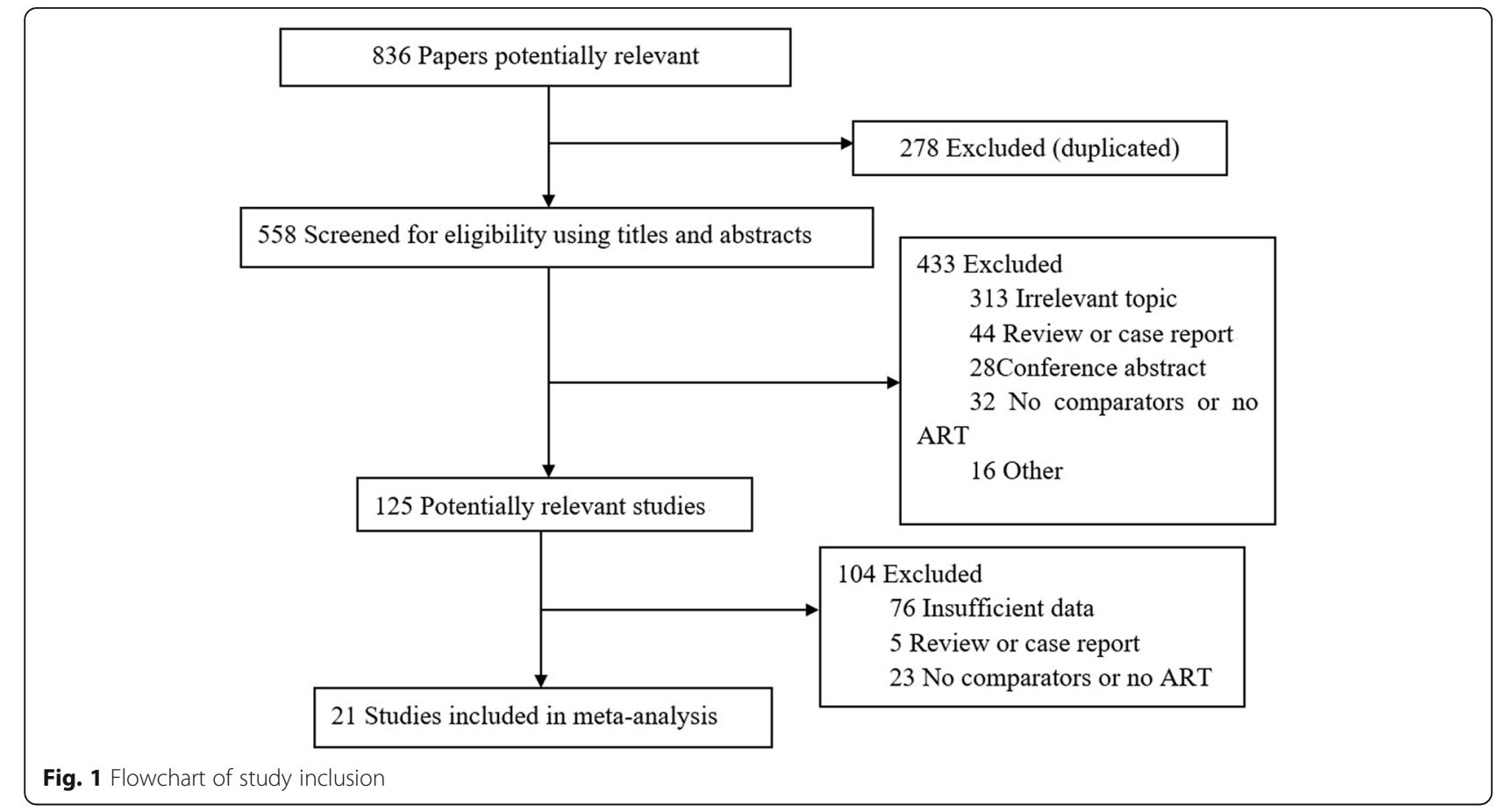

\section{Efficacy of ART in terms of 5-year OS}

The results showed a significant improvement in the 5-year OS with ART (with or without CT) compared with no ART (Fig. 2) (OR $=0.63$; 95\% confidence interval [CI] 0.50$0.81 ; p=0.0002)$. No significant heterogeneity existed among the included studies $\left(\mathrm{I}^{2}, 15 \% ; p=0.26\right)$. Five studies reported the 5 -year OS of patients with lymph nodepositive disease, and four studies reported the 5-year OS after margin-positive resection. Both analyses showed improvement in the 5-year OS with ART $(\mathrm{OR}=0.15,95 \% \mathrm{CI}$ $0.07-0.35, p<0.00001$, Fig. 3; OR $=0.40$; 95\% CI 0.19-0.85; $p=0.02$, Fig. 4 , respectively). No significant heterogeneity existed among the included studies $\left(\mathrm{I}^{2}, 24 \%, p=0.26 ; \mathrm{I}^{2}\right.$, $31 \%, p=0.23$ ). Three studies reported the 5 -year OS of patients with margin-negative disease, and the meta-analysis results showed that patients could gain a relative benefit from ART but the difference was not statistically significant $(\mathrm{OR}=0.57,95 \%$ CI 0.30-1.07, $p=0.08$, Fig. 5).

\section{Efficacy of ART in terms of local tumor control}

Eleven studies reported the influence of ART on local tumor control. Subsequent analysis of these studies revealed that ART significantly reduced the risk of local recurrence $(\mathrm{OR}=0.54 ; 95 \%$ CI $0.38-0.76 ; p=0.0004$, Fig. 6). The included studies had no significant heterogeneity $\left(\mathrm{I}^{2}, 32 \% ; p=0.14\right)$.

\section{Efficacy of ART in terms of distant metastasis}

Ten studies reported the impact of ART on distant metastasis. Pooled data showed a nonsignificant effect of ART compared with surgery alone on distant metastasis
$(\mathrm{OR}=1.33$; 95\% CI 0.97-1.87; $p=0.1$, Fig. 7). Significant heterogeneity was found among the included studies $\left(\mathrm{I}^{2}\right.$, $39 \% ; p=0.09$ ). The studies by Kim et al. [24] and Todoroki et al. [32], who reported the least favorable effects of ART, were the main contributors to this heterogeneity. After exclusion of these two studies, the heterogeneity was not significant $\left(\mathrm{I}^{2}, 0 \% ; p=0.5\right)$, but the effects of ART remained nonsignificant (OR 1.09; 95\% CI 0.75-1.57; $p=0.66$ ).

\section{Toxicities}

The toxicities reported in the included studies are shown in Table 2. Acute and late toxicities were generally tolerable. The rates of grade 3 or higher acute toxicity (nausea, vomiting, diarrhea, bone marrow suppression, etc.) and chronic toxicity (gastrointestinal bleeding and ulcer, digestive tract obstruction, bile duct stricture, etc.) were low. A few patients required surgery because of severe toxic reactions, such as bleeding and stenosis.

\section{Literature publication bias evaluation}

The publication bias of the included studies is shown in Table 3. The $p$ value for publication bias regarding the overall 5 -year OS was $<0.05$, suggesting the presence of publication bias, and the remaining comparisons had a $p$ value of $>0.05$, indicating no significant publication bias. Egger's regression test showed that publication bias existed in the 5-year OS. The scissor method showed that the combined results of the effect indicators before and after clipping were 0.468 (95\% CI, 0.216-0.720) and $0.242(0.011-0.474)$, respectively, using the fixed effects model and 0.523 (95\% CI, 0.229-0.818) and 0.270 (- 


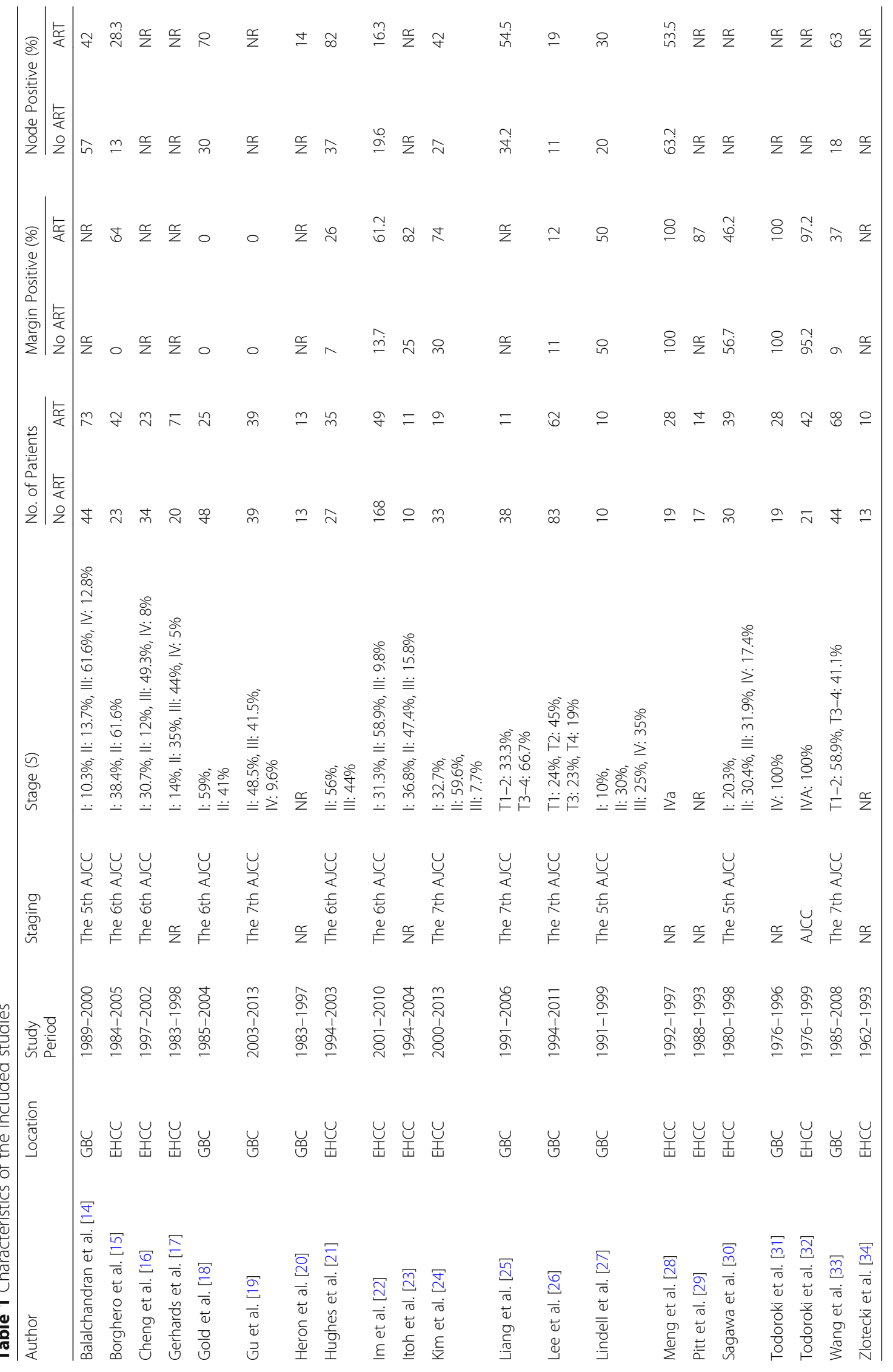




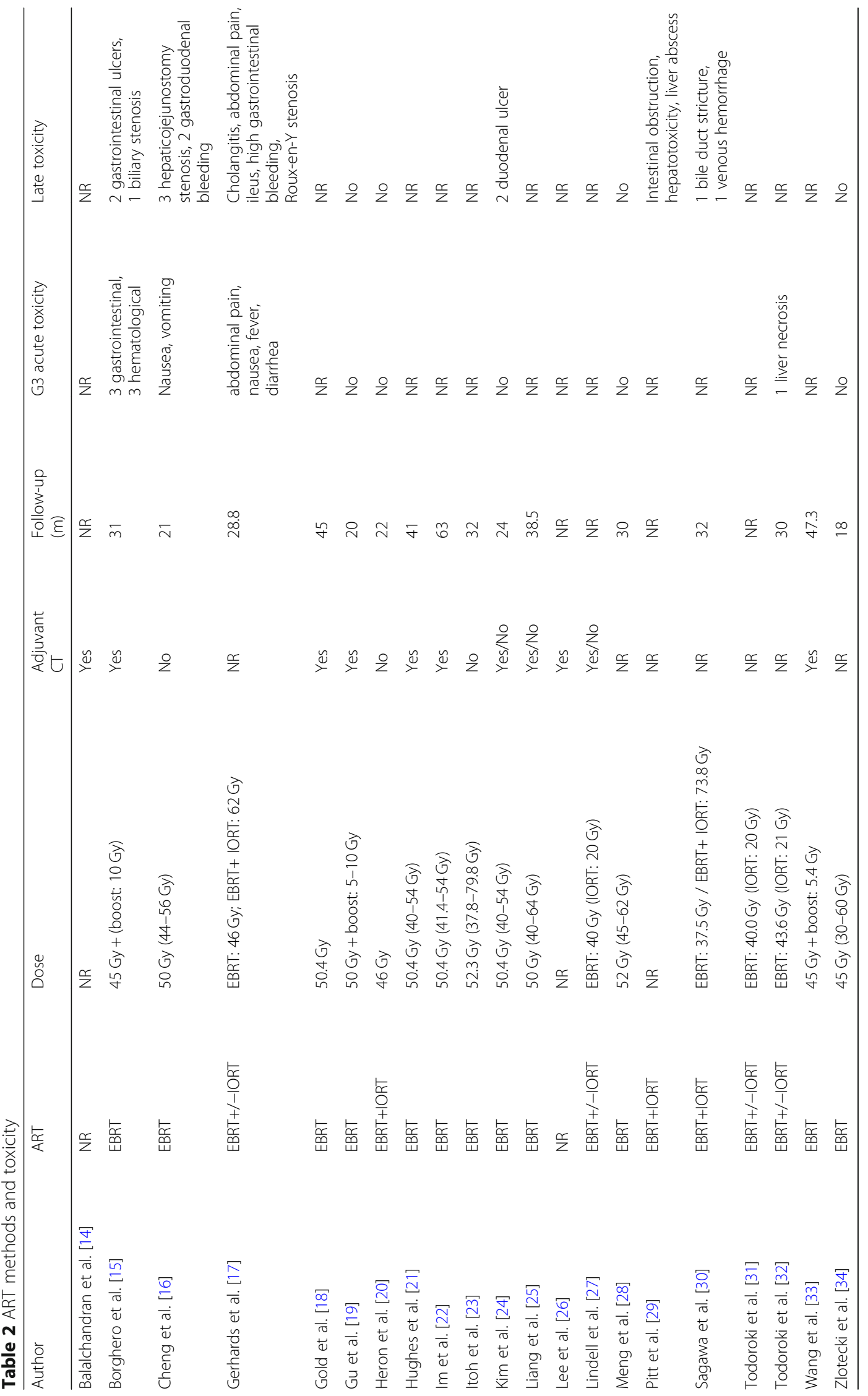




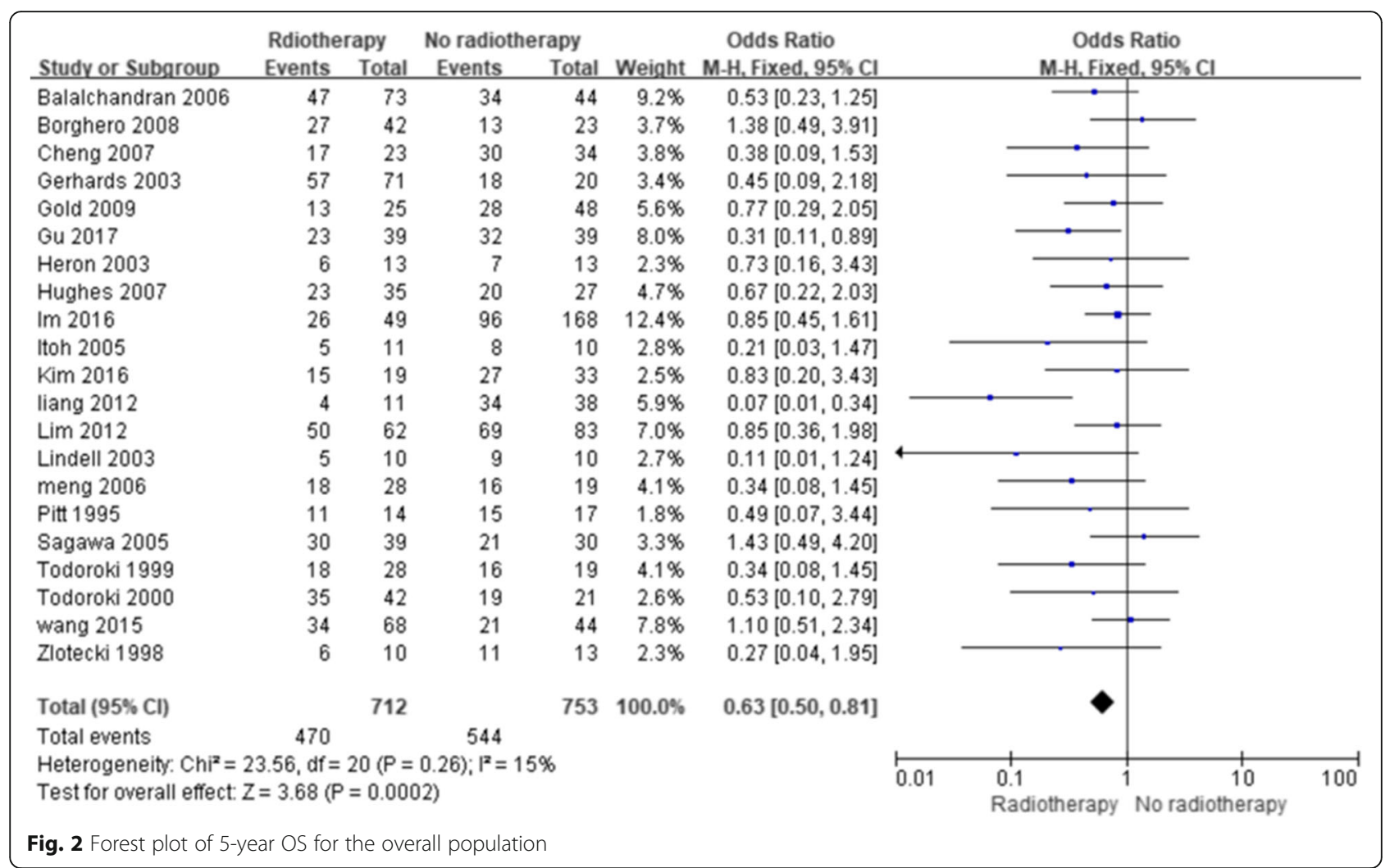

0.058-0.599), respectively, using the random effects model. The results changed only slightly, indicating that the results in the literature were robust and that publication bias had little effect on the results.

\section{Discussion}

This analysis included 21 studies (involving 1465 patients) that assessed the impact of ART on GBC and EHCC. In this comprehensive review and meta-analysis, we found that patients who received ART had a significantly better 5-year OS rate and lower local recurrence rate than those who did not receive ART. The results of our study were, to some degree, consistent with those of previous meta-analyses [35-37]. Horgan et al. concluded that adjuvant therapy was beneficial for high-risk biliary tract cancer patients, including those with lymph nodepositive disease (HR, 0.49; 95\% CI, 0.30-0.80) and those who underwent margin-positive resection (HR, 0.36; 95\% CI, 0.19-0.68) [35]. Kim et al. reported that ART reduced the risk of death ( $\mathrm{HR}, 0.54 ; 95 \%$ CI 0.44-0.67; $p<0.001)$ and recurrence (HR, 0.61; 95\% CI, 0.38-0.98; $p=0.04$ ) among patients with GBC [37]. However, being different from these studies, our study included several retrospective studies assessing the role of ART that were published recently, and we focused on the long-term (5year) survival benefit of ART. In particular, we analyzed

\begin{tabular}{|c|c|c|c|c|c|c|c|c|c|c|}
\hline \multirow[b]{2}{*}{ Study or Subgroup } & \multicolumn{2}{|c|}{ Radiotherapy } & \multicolumn{2}{|c|}{ No radiotherapy } & \multirow{2}{*}{ Weight } & \multirow{2}{*}{$\begin{array}{c}\text { Odds Ratio } \\
\text { M- } \mathrm{H} \text {, Fixed, } 95 \% \mathrm{Cl}\end{array}$} & \multirow{2}{*}{\multicolumn{4}{|c|}{$\begin{array}{c}\text { Odds Ratio } \\
\text { M- } \mathrm{H} \text {, Fixed, } 95 \% \mathrm{Cl}\end{array}$}} \\
\hline & Events & Total & Events & Total & & & & & & \\
\hline Hughes 2007 & 0 & 28 & 8 & 11 & $33.2 \%$ & $0.01[0.00,0.15]$ & $\longleftarrow$ & 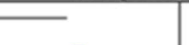 & & \\
\hline Im 2016 & 11 & 20 & 19 & 22 & $22.9 \%$ & $0.19[0.04,0.87]$ & & & & \\
\hline Todoroki 1999 & 23 & 28 & 19 & 19 & $12.3 \%$ & $0.11[0.01,2.11]$ & & & & \\
\hline Todoroki 2000 & 18 & 28 & 16 & 19 & $19.1 \%$ & $0.34[0.08,1.45]$ & & & - & \\
\hline Wang 2015 & 26 & 42 & 7 & 8 & $12.6 \%$ & $0.23[0.03,2.07]$ & & & & \\
\hline Total $(95 \% \mathrm{CI})$ & & 146 & & 79 & $100.0 \%$ & $0.15[0.07,0.35]$ & & & & \\
\hline Total events & 78 & & 69 & & & & & & & \\
\hline \multicolumn{7}{|c|}{$\begin{array}{l}\text { Heterogeneity. } C i^{2}=5.23, d f=4(P=0.26) ; I^{2}=24 \% \\
\text { Test for overall effect: } Z=4.51(P<0.00001)\end{array}$} & 0.01 & $\begin{array}{ll}0.1 & 1 \\
\text { Radiotherapy }\end{array}$ & $10 \frac{10}{\text { No radiotherapy }}$ & 100 \\
\hline
\end{tabular}




\begin{tabular}{|c|c|c|c|c|c|c|c|c|c|c|}
\hline \multirow[b]{2}{*}{ Study or Subgroup } & \multicolumn{2}{|c|}{ Radiotherapy } & \multicolumn{2}{|c|}{ No radiotherapy } & & Odds Ratio & & \multirow{2}{*}{\multicolumn{2}{|c|}{$\begin{array}{c}\text { Odds Ratio } \\
\text { M-H, Fixed, 95\% Cl }\end{array}$}} & \\
\hline & Events & Total & Events & Total & Weight & M-H, Fixed, 95\% Cl & & & & \\
\hline $\operatorname{Im} 2016$ & 11 & 20 & 19 & 22 & $36.1 \%$ & $0.19[0.04,0.87]$ & & & & \\
\hline Meng 2006 & 18 & 28 & 16 & 19 & $30.2 \%$ & $0.34[0.08,1.45]$ & & & - & \\
\hline Sagawa 2005 & 17 & 18 & 14 & 17 & $3.5 \%$ & $3.64[0.34,39.01]$ & & & & \\
\hline Todoroki 2000 & 18 & 28 & 16 & 19 & $30.2 \%$ & $0.34[0.08,1.45]$ & & & E & \\
\hline Total $(95 \% \mathrm{Cl})$ & & 94 & & 77 & $100.0 \%$ & $0.40[0.19,0.85]$ & & & & \\
\hline \multirow{2}{*}{\multicolumn{7}{|c|}{$\begin{array}{l}\text { Total events } \quad 64 \quad 65 \\
\text { Heterogeneity: } \mathrm{Chi}^{2}=4.35, \mathrm{df}=3(P=0.23) ; \mathrm{I}^{2}=31 \% \\
\text { Test for overall effect: } Z=2.38(P=0.02)\end{array}$}} & & & & \\
\hline & & & & & & & 0.01 & $\begin{array}{l}0.1 \\
\text { Radiotherapy }\end{array}$ & $\begin{array}{cc}10 \\
\text { No radiotherapy }\end{array}$ & 100 \\
\hline
\end{tabular}

the effect of ART on local recurrence and distant metastasis. Our results suggest that ART is warranted and should be considered in prospective studies involving GBC or EHCC. Currently, there is no standard adjuvant treatment for patients with GBC or EHCC, and the controversy regarding whether the addition of ART improves OS in these patients has not yet been resolved [38-43]. Data are emerging from several prospective trials on the efficiency of adjuvant chemotherapy for GBC or biliary tract cancers, but prospective trials involving ART are scarce [44-46]. The BILCAP trial suggested that capecitabine, comparing with observation, can improve OS in patients with resected biliary tract cancer when used as adjuvant chemotherapy following surgery; however, this study did not meet its primary endpoint of improving OS in the intention-to treat population [44]. In a randomized phase III study conducted by Edeline J et al., adjuvant gemcitabine and oxaliplatin was found to offer no benefit in resected biliary tract cancer patients [45]. From the two trials, we can see that the benefit of adjuvant $\mathrm{CT}$ was unclear and patients may not receive much benefit from adjuvant $\mathrm{CT}$, so it is necessary to explore the effect of ART with or without adjuvant CT. Recently, the SWOG 0809 trial of GBC and EHCC, a prospective single-arm trial, demonstrated that gemcitabine and capecitabine followed by concurrent capecitabine and radiotherapy had promising efficacy and the toxicity was acceptable [2]. Tran Cao et al. reported that ART was associated with a lower risk of death relative to surgery alone for patients with lymph node-positive GBC regardless of margin status (margin-negative resection: HR, 0.66; 95\% CI, 0.52-0.84; margin-positive resection: HR, 0.54; 95\% CI, 0.39-0.75) [47]. Lau et al. showed that the combination of surgery and radiation resulted in significantly longer survival than surgery alone (4.0 versus 3.7 years, $p=0.0004$ ) [48]. However, some studies have shown that ART cannot benefit GBC and EHCC patients. For example, Leng et al. reported that ART did not improve the OS (22 vs 23 months, $p=0.978$ ) of patients with curative intent resection of perihilar cholangiocarcinoma [49]. Among the studies in our meta-analysis, Borghero et al. [15] concluded that ART did not benefit patients, but the margins were negative in the observation group, and the margin-positive rate in the radiotherapy group was $64 \%$. Therefore, the failure of radiotherapy to improve the 5-year OS may be due to the higher proportion of margin-positive patients in the radiotherapy group.

Some special points need to be noted in our study. Given the retrospective nature of these studies on GBC or EHCC patients who underwent surgery, it is reasonable to assume that a majority of the included patients who received ART were selected because of high-risk features, as our study showed that patients who received ART are more likely to have lymph node- and margin-positive disease. Thus, it is difficult to draw a conclusion on the best treatment for low-risk patients. In our analysis, only 3 studies reported the 5-year OS of patients with margin-negative disease, and we could not evaluate the effect of ART on lymph node-negative disease. Other details, such as the lymph

\begin{tabular}{|c|c|c|c|c|c|c|c|c|c|c|}
\hline \multirow[b]{2}{*}{ Study or Subgroup } & \multicolumn{2}{|c|}{ Radiotherapy } & \multicolumn{2}{|c|}{ No radiotherapy } & \multirow{2}{*}{ Weight } & \multirow{2}{*}{$\begin{array}{c}\text { Odds Ratio } \\
\text { M- } \mathrm{H} \text {, Fixed, } 95 \% \mathrm{Cl}\end{array}$} & \multirow{2}{*}{\multicolumn{4}{|c|}{$\begin{array}{c}\text { Odds Ratio } \\
\text { M-H. Fixed, 95\% Cl }\end{array}$}} \\
\hline & Events & Total & Events & Total & & & & & & \\
\hline Gold 2009 & 13 & 25 & 28 & 48 & $36.0 \%$ & $0.77[0.29,2.05]$ & & $\square$ & 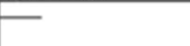 & \\
\hline Gu 2017 & 23 & 39 & 32 & 39 & $51.4 \%$ & $0.31[0.11,0.89]$ & & & & \\
\hline Sagawa 2005 & 7 & 13 & 7 & 13 & $12.6 \%$ & $1.00[0.21,4.67]$ & & & & \\
\hline Total $(95 \% \mathrm{Cl})$ & & 77 & & 100 & $100.0 \%$ & $0.57[0.30,1.07]$ & & & & \\
\hline Total events & 43 & & 67 & & & & & & & \\
\hline $\begin{array}{l}\text { Heterogeneity: } \mathrm{Chi}^{2}= \\
\text { Test for overall effect }\end{array}$ & $\begin{array}{l}2.15, d f= \\
Z=1.76(f\end{array}$ & $\begin{array}{l}(P=0.3 \\
=0.08)\end{array}$ & $34) ; 1^{2}=7 x$ & & & & 0.01 & $\begin{array}{cc}0.1 & 1 \\
\text { Radiotherapy }\end{array}$ & $\begin{array}{c}10 \\
\text { No radiotheray }\end{array}$ & 100 \\
\hline
\end{tabular}




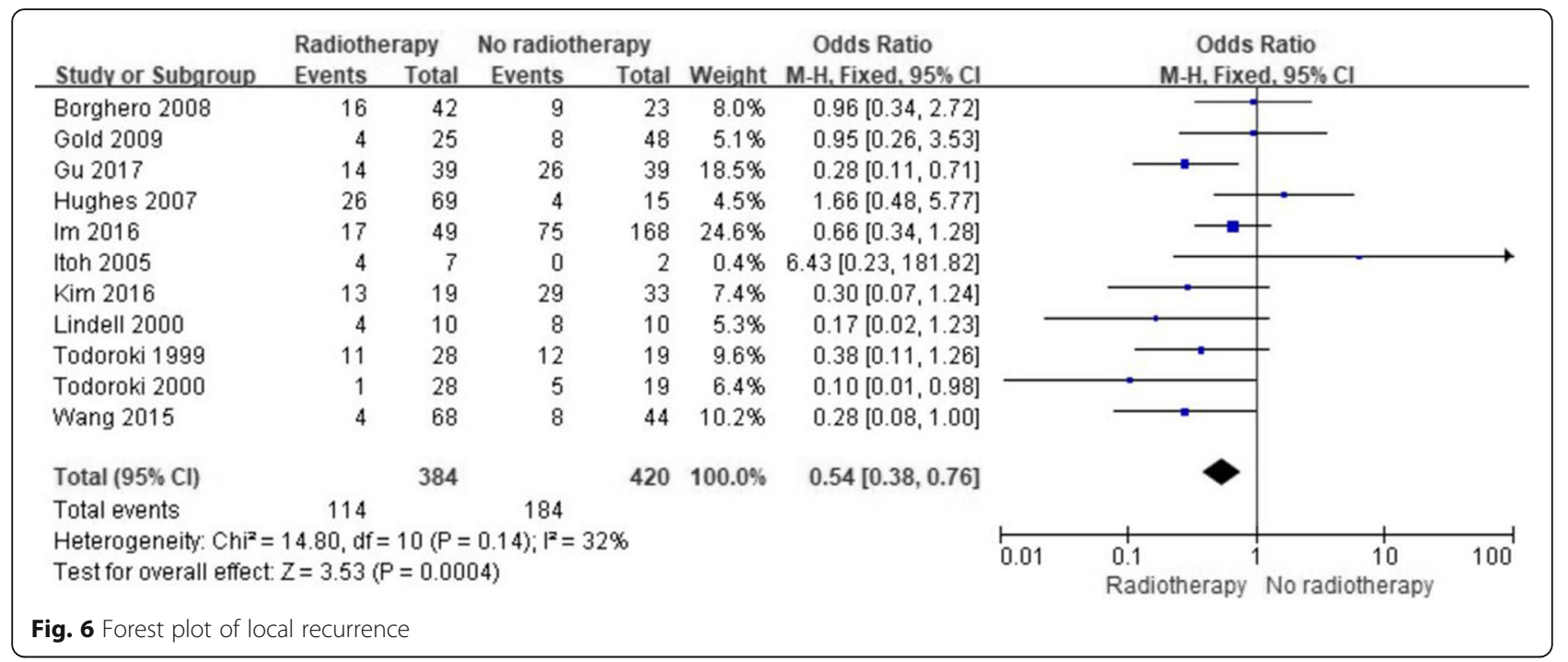

node and margin status and the corresponding 5-year OS, were not always reported in the 21 studies. Thus, only five studies reported the effects of ART on patients with lymph node-positive disease, and four studies reported such data on those with margin-positive disease. Therefore, the results of the three analyses should be interpreted with extreme caution.

In terms of toxicity regarding adjuvant therapy, ASCO clinical practice guidelines for adjuvant therapy for resected biliary tract cancer indicate the risk of potential harm associated with radiation therapy for patients with GBC and EHCC [40]. However, in our included studies, the toxic reactions to radiotherapy were tolerable, and the incidence of acute toxicity above grade 3 (such as nausea, vomiting, diarrhea, bone marrow suppression, etc.) and chronic toxicity (such as peptic ulcer, gastrointestinal bleeding, digestive tract obstruction, bile duct stricture, etc.) was low. Severe toxic reactions, such as bleeding and stenosis requiring surgery, were rare.

This study also had several limitations. First and foremost, all the included studies were retrospective analyses and influenced by selection bias and treatment variations during the study period. However, all of these studies compared ART with no ART, and they all evaluated the same endpoints. Thus, we think that a meta-analysis is warranted to confirm the effect of ART on GBC and EHCC patients. Second, the number of patients included in each study was relatively small. Considering that registry study information is always incomplete and may overlap with institutional study information, we excluded registry studies. Third, due to the lack of relevant data, the efficacy of postoperative ART alone cannot be assessed, and because not all studies reported other details such as pathological condition and grade, it was difficult to draw conclusions regarding the

\begin{tabular}{|c|c|c|c|c|c|c|c|c|c|c|}
\hline \multirow[b]{2}{*}{ Study or Subgroup } & \multicolumn{2}{|c|}{ Radiotherapy } & \multicolumn{2}{|c|}{ No radiotherapy } & \multirow{2}{*}{ Weight } & \multirow{2}{*}{$\begin{array}{c}\text { Odds Ratio } \\
\text { M- } \mathrm{H} \text {, Fixed, } 95 \% \mathrm{Cl}\end{array}$} & \multirow{2}{*}{\multicolumn{4}{|c|}{$\begin{array}{c}\text { Odds Ratio } \\
\text { M-H, Fixed, } 95 \% \mathrm{Cl}\end{array}$}} \\
\hline & Events & Total & Events & Total & & & & & & \\
\hline Borghero 2008 & 10 & 42 & 2 & 23 & $3.4 \%$ & $3.28[0.65,16.50]$ & & 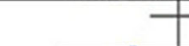 & & \\
\hline Gerhards 2003 & 34 & 69 & 10 & 15 & $14.3 \%$ & $0.49[0.15,1.57]$ & & & 一 & \\
\hline Gold 2009 & 8 & 25 & 13 & 48 & $10.4 \%$ & $1.27[0.44,3.64]$ & & & & \\
\hline Gu 2017 & 13 & 39 & 10 & 39 & $11.5 \%$ & $1.45[0.54,3.86]$ & & & & \\
\hline $\operatorname{Im} 2016$ & 20 & 49 & 78 & 168 & $35.8 \%$ & $0.80[0.42,1.52]$ & & $\rightarrow$ & E & \\
\hline Kim 2016 & 7 & 19 & 3 & 33 & $2.4 \%$ & $5.83[1.29,26.38]$ & & & & \\
\hline Lindell 2003 & 1 & 10 & 2 & 10 & $3.1 \%$ & $0.44[0.03,5.88]$ & & & & \\
\hline Todoroki 1999 & 25 & 28 & 15 & 19 & $3.3 \%$ & $2.22[0.44,11.32]$ & & & & \\
\hline Todoroki 2000 & 14 & 28 & 3 & 19 & $3.1 \%$ & $5.33[1.27,22.48]$ & & & & \\
\hline Wang 2015 & 16 & 68 & 8 & 44 & $12.8 \%$ & $1.38[0.54,3.58]$ & & & 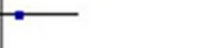 & \\
\hline Total $(95 \% \mathrm{Cl})$ & & 377 & & 418 & $100.0 \%$ & $1.33[0.95,1.87]$ & & & & \\
\hline Total events & 148 & & 144 & & & & & & & \\
\hline \multicolumn{7}{|c|}{$\begin{array}{l}\text { Heterogeneity: } \mathrm{Chi}^{2}=14.86, \mathrm{df}=9(\mathrm{P}=0.09) ; \mathrm{I}^{2}=39 \% \\
\text { Test for overall effect: } Z=1.65(P=0.10)\end{array}$} & 0.01 & $\begin{array}{ll}0.1 & 1 \\
\text { Radiotherapy }\end{array}$ & $\begin{array}{c}10 \\
\text { No radiotherapy }\end{array}$ & $\overrightarrow{100}$ \\
\hline
\end{tabular}


Table 3 Evaluation of publication bias in the included literature

\begin{tabular}{llllll}
\hline Evaluation index & Coef. & Std. Err. & $\mathrm{t}$ & $\mathrm{P}$ & $95 \% \mathrm{Cl}$ \\
\hline 5-year OS & 1.95 & 0.59 & 3.32 & 0.004 & $0.72-3.17$ \\
5-year OS of LN+ & 2.59 & 1.26 & 2.05 & 0.13 & $-1.43-6.60$ \\
5-year OS of R+ & -5.97 & 1.60 & -3.74 & 0.07 & $-12.83-0.90$ \\
5-year OS of R- & -1.84 & 4.12 & -0.45 & 0.73 & $-54.23-50.56$ \\
Local recurrence & -0.35 & 1.03 & -0.34 & 0.74 & $-2.67-1.98$ \\
Distant metastasis & 1.65 & 1.10 & 1.51 & 0.17 & $-0.87-4.16$ \\
\hline
\end{tabular}

best treatment for low-risk patients with early-stage, lymph node-negative disease.

\section{Conclusion}

GBC and EHCC are rare and aggressive tumors for which there is no standard adjuvant treatment. Our study provides supporting evidence for the clinical application of ART in GBC and EHCC. The subgroup analysis in our study showed that patients at high risk due to lymph nodepositive disease and margin-positive disease can benefit from ART. For patients with margin-negative disease, ART also had a trend to improve 5-year OS. We also conclude that ART can reduce the rate of local recurrence but does not affect the distant metastasis rate. Considering that no prospective trial has evaluated the effect of ART on GBC and EHCC, our study may contribute to the rational design of a prospective study and provide a reference for clinical treatment.

\section{Abbreviations}

ART: Adjuvant radiotherapy; Cl: Confidence interval; CNKI: China National Knowledge Infrastructure; CT: Chemotherapy; EHCC: Extrahepatic cholangiocarcinoma; GBC: Gallbladder carcinoma; HR: Hazard ratio; OR: Odds ratio; OS: Overall survival

\section{Acknowledgements}

Not applicable.

\section{Authors' contributions}

BR, QG and YY conceived and coordinated the study, designed, performed, and analyzed the experiments, and wrote the manuscript. LL, SW and WC collected and analyzed the data. YT revised the manuscript. All authors reviewed the results and approved the final version of the manuscript.

\section{Funding}

This study was financially supported by the Jiangsu Provincial Key Project (BE2018657), the Jiangsu Medical Innovation Team (No. CXDT-37), and the Suzhou Introduced Project of Clinical Medical Expert Team (SZYJTD201804).

\section{Availability of data and materials}

All data generated or analyzed during this study are included in this manuscript.

\section{Ethics approval and consent to participate}

Not applicable.

\section{Consent for publication}

Not applicable.

\section{Competing interests}

The authors declare that they have no competing interests.

\section{Author details}

${ }^{1}$ Department of Radiotherapy \& Oncology, The Second Affiliated Hospital of Soochow University, Suzhou, China. ${ }^{2}$ Institute of Radiotherapy \& Oncology, Soochow University, Suzhou, China. ${ }^{3}$ Suzhou Key Laboratory for Radiation Oncology, San Xiang Road No. 1055, Suzhou 215004, Jiangsu, China.

${ }^{4}$ Department of General Surgery, The Second Affiliated Hospital of Soochow University, Suzhou 215004, China.

Received: 30 July 2019 Accepted: 5 January 2020

Published online: 15 January 2020

\section{References}

1. Siegel RL, Miller KD, Jemal A. Cancer statistics, 2019. CA Cancer J Clin. 2019; 69(1):7-34. https://doi.org/10.3322/caac.21551.

2. Ben-Josef E, Guthrie KA, El-Khoueiry AB, Corless CL, Zalupski MM, Lowy AM, et al. SWOG S0809: a phase II intergroup trial of adjuvant Capecitabine and gemcitabine followed by radiotherapy and concurrent Capecitabine in Extrahepatic Cholangiocarcinoma and gallbladder carcinoma. J Clin Oncol. 2015;33(24):2617-22. https://doi.org/10.1200/JCO.2014.60.2219.

3. Doherty B, Nambudiri VE, Palmer WC. Update on the diagnosis and treatment of Cholangiocarcinoma. Curr Gastroenterol Rep. 2017;19(1):2. https://doi.org/10.1007/s11894-017-0542-4.

4. Razumilava N, Gores GJ. Cholangiocarcinoma. Lancet. 2014;383(9935):216879. https://doi.org/10.1016/S0140-6736(13)61903-0.

5. Javle M, Bekaii-Saab T, Jain A, Wang Y, Kelley RK, Wang K, et al. Biliary Cancer: utility of next-generation sequencing for clinical management. Cancer. 2016;122(24):3838-47. https://doi.org/10.1002/cncr.30254.

6. Mehrotra R, Tulsyan S, Hussain S, Mittal B, Singh Saluja S, Singh S, et al. Genetic landscape of gallbladder cancer: global overview. Mutat Res. 2018; 778:61-71. https://doi.org/10.1016/j.mrrev.2018.08.003.

7. Malka D, Cervera P, Foulon S, Trarbach $T$, de la Fouchardière $C$, Boucher $E$, et al. Gemcitabine and oxaliplatin with or without cetuximab in advanced biliary-tract cancer (BINGO): a randomised, open-label, non-comparative phase 2 trial. Lancet Oncol. 2014;15(8):819-28. https://doi.org/10.1016/ S1470-2045(14)70212-8.

8. Takahashi Y, Ebata T, Yokoyama Y, Igami T, Sugawara G, Mizuno T, et al. Surgery for recurrent biliary tract Cancer: a single-center experience with 74 consecutive resections. Ann Surg. 2015;262(1):121-9. https://doi.org/10. 1097/SLA.0000000000000827.

9. Hu G, Liu Q, Ma JY, Liu CY. Prognostic significance of platelet-to-lymphocyte ratio in Cholangiocarcinoma: a meta-analysis. Biomed Res Int. 2018;2018: 7375169. https://doi.org/10.1155/2018/7375169.

10. Boimel PJ, Binder KR, Hong TS, Feng M, Ben-Josef E. Cholangiocarcinoma and gallbladder cases: an expert panel case-based discussion. Semin Radiat Oncol. 2018;28(4):351-61. https://doi.org/10.1016/j.semradonc.2018.06.004.

11. Ecker BL, Vining CC, Roses RE, Maggino L, Lee MK, Drebin JA, et al. Identification of patients for adjuvant therapy after resection of carcinoma of the Extrahepatic bile ducts: a propensity score-matched analysis. Ann Surg Oncol. 2017;24(13):3926-33. https://doi.org/10.1245/s10434-017-6095-9.

12. Shinohara ET, Mitra N, Guo M, Metz JM. Radiotherapy is associated with improved survival in adjuvant and palliative treatment of extrahepatic cholangiocarcinoma. Int J Radiat Oncol Biol Phys. 2009;74(4):1191-8. https:// doi.org/10.1016/j.jijobp.2008.09.017.

13. Shinohara ET, Mitra N, Guo M, Metz JM. Survival outcomes in resected extrahepatic cholangiocarcinoma: effect of adjuvant radiotherapy in a surveillance, epidemiology, and end results analysis. Int J Radiat Oncol Biol Phys. 2011;81(1):189-98. https://doi.org/10.1016/j.jirobp.2010.05.001.

14. Balachandran P, Agarwal S, Krishnani N, Pandey CM, Kumar A, Sikora SS, et al. Predictors of long-term survival in patients with gallbladder cancer. J Gastrointest Surg. 2006;10(6):848-54. https://doi.org/10.1016/j. gassur.2005.12.002

15. Borghero Y, Crane CH, Szklaruk J, Oyarzo M, Curley S, Pisters PW, et al. Extrahepatic bile duct adenocarcinoma: patients at high-risk for local recurrence treated with surgery and adjuvant Chemoradiation have an equivalent overall survival to patients with standard-risk treated with surgery alone. Ann Surg Oncol. 2008;15(11):3147-56. https://doi.org/10. 1245/s10434-008-9998-7.

16. Cheng Q, Luo X, Zhang B, Jiang X, Yi B, Wu M. Predictive factors for prognosis of hilar cholangiocarcinoma: Postresection radiotherapy improves survival. Eur J Surg Oncol. 2007;33(2):202-7. https://doi.org/10.1016/j.ejso.2006.09.033. 
17. Gerhards MF, van Gulik TM, González González D, Rauws EA, Gouma DJ. Results of postoperative radiotherapy for Resectable Hilar Cholangiocarcinoma. World J Surg. 2003;27(2):173-9. https://doi.org/10. 1007/s00268-002-6434-1.

18. Gold DG, Miller RC, Haddock MG, Gunderson LL, Quevedo F, Donohue JH, et al. Adjuvant therapy for gallbladder carcinoma: the Mayo Clinic experience. Int J Radiat Oncol Biol Phys. 2009;75(1):150-5. https://doi.org/10, 1016/j.jijobp.2008.10.052.

19. Gu B, Qian L, Yu H, Hu J, Wang Q, Shan J, et al. Concurrent Chemoradiotherapy in curatively resected gallbladder carcinoma: a propensity score-matched analysis. Int J Radiat Oncol Biol Phys. 2018;100(1): 138-45. https://doi.org/10.1016/j.jijrobp.2017.09.029.

20. Heron DE, Stein DE, Eschelman DJ, Topham AK, Waterman FM, Rosato EL, et al. Cholangiocarcinoma: the impact of tumor location and treatment strategy on outcome. Am J Clin Oncol. 2003;26(4):422-8. https://doi.org/10. 1097/01.COC.0000026833.73428.1F.

21. Hughes MA, Frassica DA, Yeo CJ, Riall TS, Lillemoe KD, Cameron JL, et al. Adjuvant concurrent chemoradation for adenocarcinoma of the distal common bile duct. Int J Radiat Oncol Biol Phys. 2007;68(1):178-2. https:// doi.org/10.1016/j.jijobp.2006.11.048.

22. Im JH, Seong J, Lee IJ, Park JS, Yoon DS, Kim KS, et al. Surgery alone versus surgery followed by chemotherapy and radiotherapy in resected Extrahepatic bile duct Cancer: treatment outcome analysis of 336 patients. Cancer Res Treat. 2016;48(2):583-95. https://doi.org/10.4143/crt.2015.091.

23. Itoh H, Nishijima K, Kurosaka Y, Takegawa S, Kiriyama M, Dohba S, et al. Magnitude of combination therapy of radical resection and external beam radiotherapy for patients with carcinomas of the extrahepatic bile duct and gallbladder. Dig Dis Sci. 2005;50(12):2231-42. https://doi.org/10.1007/ s10620-005-3040-8.

24. Kim WS, Choi DW, You DD, Ho CY, Heo JS, Choi SH. Risk factors influencing recurrence, patterns of recurrence, and the efficacy of adjuvant therapy after radical resection for gallbladder carcinoma. J Gastrointest Surg. 2010;14(4): 679-87. https://doi.org/10.1007/s11605-009-1140-z.

25. Liang JW, Wang Z, Zhou ZX, et al. Value of postoperative adjuvant therapy for gallbladder carcinoma. Chin J Gen Surg. 2012;27(6):445-8. https://doi. org/10.3760/cma.jim.1007-631X.2012.06.003.

26. Lee HY, Kim YH, Jung GJ, Roh YH, Park SY, Kang NU, et al. Prognostic factors for gallbladder cancer in the laparoscopy era. J Korean Surg Soc. 2012;83(4): 227-36. https://doi.org/10.4174/jkss.2012.83.4.227.

27. Lindell G, Holmin T, Ewers SB, Tranberg KG, Stenram U, Ihse I. Extended operation with or without intraoperative (IORT) and external (EBRT) radiotherapy for gallbladder carcinoma. Hepatogastroenterology. 2003; 50(50):310-4.

28. Meng $Y$, Xiao ZP, Zhang BH. The value of radiotherapy after radical resection of locally advanced hilar cholangiocarcinoma. Chin J Radiat Oncol. 2006;15(2):114-6. https://doi.org/10.3760/j.issn:1004-4221.2006.02.010.

29. Pitt HA, Nakeeb A, Abrams RA, Coleman J, Piantadosi S, Yeo CJ, et al. Perihilar cholangiocarcinoma: postoperative radiotherapy does not improve survival. Ann Surg. 1995;221(6):788-97.

30. Sagawa N, Kondo S, Morikawa T, Okushiba S, Katoh H. Effectiveness of radiation therapy after surgery for hilar cholangiocarcinoma. Surg Today. 2005;35(7):548-52. https://doi.org/10.1007/s00595-005-2989-4.

31. Todoroki T, Kawamoto T, Otsuka M, Koike N, Yoshida S, Takada Y, et al. Benefits of combining radiotherapy with aggressive resection for stage IV gallbladder cancer. Hepatogastroenterology. 1999;46(27):1585-91.

32. Todoroki T, Ohara K, Kawamoto T, Koike N, Yoshida S, Kashiwagi H, et al. Benefits of adjuvant radiotherapy after radical resection of locally advanced main hepatic duct carcinoma. Int I Radiat Oncol Biol Phys. 2000;46(3):581-7.

33. Wang J, Narang AK, Sugar EA, Luber B, Rosati LM, Hsu CC, et al. Evaluation of adjuvant radiation therapy for resected gallbladder carcinoma: a multiinstitutional experience. Ann Surg Oncol. 2015;22(S3):1 100-6. https://doi. org/10.1245/s10434-015-4685-y.

34. Zlotecki RA, Jung LA, Vauthey JN, Vogel SB, Mendenhall WM. Carcinoma of the extrahepatic biliary tract: surgery and radiotherapy for curative and palliative intent. Radiat Oncol Investig. 1998;6:240-7. https://doi.org/10.1002/ (SICI)1520-6823(1998)6:5<240::AID-ROI6>3.0.CO;2-R.

35. Horgan AM, Amir E, Walter T, Knox JJ. Adjuvant therapy in the treatment of biliary tract Cancer: a systematic review and meta-analysis. J Clin Oncol. 2012;30(16):1934-40. https://doi.org/10.1200/JCO.2011.40.5381.

36. Bonet Beltrán M, Allal AS, Gich I, Solé JM, Carrió I. Is adjuvant radiotherapy needed after curative resection of extrahepatic biliary tract cancers? A systematic review with a meta-analysis of observational studies. Cancer Treat Rev. 2012:38(2):111-9. https://doi.org/10.1016/j.ctrv.2011.05.003.

37. Kim BH, Kwon J, Chie EK, Kim K, Kim YH, Seo DW, et al. Adjuvant Chemoradiotherapy is associated with improved survival for patients with resected gallbladder carcinoma: a systematic review and meta-analysis. Ann Surg Oncol. 2018;25(1):255-64. https://doi.org/10.1245/s10434-017-6139-1.

38. National Comprehensive Cancer Network (NCCN). Clinical Practice Guidelines in Oncology. Hepatobiliary Cancers, Version 1. 2019. https:// www.nccn.org/patients/guidelines/hepatobiliary/index.html.

39. Valle JW, Borbath I, Khan SA, Huguet F, Gruenberger T, Arnold D. Biliary cancer: ESMO Clinical Practice Guidelines for diagnosis, treatment and follow-up. Ann Oncol. 2016;27(suppl 5):v28-37. https:/doi.org/10.1093/annonc/mdw324.

40. Shroff RT, Kennedy EB, Bachini M, Bekaii-Saab T, Crane C, Edeline J, et al. Adjuvant therapy for resected biliary tract Cancer: ASCO clinical practice guideline. J Clin Oncol. 2019;37(12):1015-27. https://doi.org/10. 1200/JCO.18.02178.

41. Miyazaki M, Yoshitomi H, Miyakawa S, Uesaka K, Unno M, Endo I, et al. Clinical practice guidelines for the management of biliary tract cancers 2015: the 2nd English edition. J Hepatobiliary Pancreat Sci. 2015;22(4):24973. https://doi.org/10.1002/jhbp.233.

42. Benavides M, Antón A, Gallego J, Gómez MA, Jiménez-Gordo A, La Casta A, et al. Biliary tract cancers: SEOM clinical guidelines. Clin Transl Oncol. 2015; 17(12):982-7. https://doi.org/10.1007/s12094-015-1436-2.

43. Brunner TB, Seufferlein T. Radiation therapy in cholangiocellular carcinomas. Best Pract Res Clin Gastroenterol. 2016;30(4):593-602. https://doi.org/10. 1016/j.bpg.2016.08.003.

44. Primrose JN, Fox RP, Palmer DH, Malik HZ, Prasad R, Mirza D, et al. Capecitabine compared with observation in resected biliary tract cancer (BILCAP): a randomised, controlled, multicentre, phase 3 study. Lancet Oncol. 2019;20(5):663-73. https://doi.org/10.1016/S1470-2045(18)30915-X.

45. Edeline J, Benabdelghani M, Bertaut A, Watelet J, Hammel P, Joly JP, et al. Gemcitabine and Oxaliplatin chemotherapy or surveillance in resected biliary tract Cancer (PRODIGE 12-ACCORD 18-UNICANCER GI): a randomized phase III study. J Clin Oncol. 2019;37(8):658-67. https://doi.org/10.1200/JCO.18.00050.

46. Stein A, Arnold D, Bridgewater J, Goldstein D, Jensen LH, Klümpen HJ, et al. Adjuvant chemotherapy with gemcitabine and cisplatin compared to observation after curative intent resection of cholangiocarcinoma and muscle invasive gallbladder carcinoma (ACTICCA-1 trial)-a randomized, multidisciplinary, multinational phase III trial. BMC Cancer. 2015;15:564. https://doi.org/10.1186/s12885-015-1498-0.

47. Tran Cao HS, Zhang Q, Sada YH, Chai C, Curley SA, Massarweh NN. The role of surgery and adjuvant therapy in lymph node-positive cancers of the gallbladder and intrahepatic bile ducts. Cancer. 2018;124(1):74-83. https:// doi.org/10.1002/cncr.30968.

48. Lau CSM, Zywot A, Mahendraraj K, Chamberlain RS. Gallbladder carcinoma in the United States: a population based clinical outcomes study involving 22,343 patients from the surveillance, epidemiology, and end result database (19732013). HPB Surg. 2017;2017:1532835. https://doi.org/10.1155/2017/1532835.

49. Leng KM, Liu YP, Wang ZD, Zhong XY, Liao GQ, Kang PC, et al. Results of adjuvant radiation therapy for locoregional perihilar cholangiocarcinoma after curative intent resection. Onco Targets Ther. 2017;10:2257-66. https:// doi.org/10.2147/OTT.S131873.

\section{Publisher's Note}

Springer Nature remains neutral with regard to jurisdictional claims in published maps and institutional affiliations.

\section{Ready to submit your research? Choose BMC and benefit from:}

- fast, convenient online submission

- thorough peer review by experienced researchers in your field

- rapid publication on acceptance

- support for research data, including large and complex data types

- gold Open Access which fosters wider collaboration and increased citations

- maximum visibility for your research: over $100 \mathrm{M}$ website views per year

At BMC, research is always in progress.

Learn more biomedcentral.com/submissions 